\title{
Education Literacy Expectations on Technology Industry Development of Humanities Revolution society 5.0 Era
}

\author{
Ade Tutty Rokhayati Rosa \\ \{rosaatrxnov@gmail.com\} \\ Postgraduate School of the Islamic University of Nusantara (UNINUS), Bandung, Indonesia
}

\begin{abstract}
The purpose of this paper is that in the concept of Society 5.0, humans must play a greater role by transforming big data into a new wisdom to improve human capacity to open opportunities for humanity to achieve meaningful life, by utilizing technology in various aspects of life. Education is one of the spearheads of society 5.0's success that must be started from the bottom. The problem is whether government policies with technology and education systems are able to collaborate to form a system that is integrated in the development of the Society5.0 in human life? The technique of collecting data from literature studies is based on books, articles, journals, $i$ the results of surveys of the use and development of technology in the industrial revolution 4.0. Critically analyzed descriptively using the theory of change approach of humanisties, digital disruption of Society's revolution disruption 5.0 It is expected that in the Industrial Revolution / Society 5.0, there will be aspects that will restore the glory of human civilization, namely aspects of collaborating with one another (physical, digital, biological, and equipped with the presence of spiritual aspects), meaning the 5.0 Society Revolution is the new future of mankind.
\end{abstract}

Keyword: Education, humanisties, industry, technology and society.

\section{Introduction}

Indonesian people are being faced with the 4.0 Industrial Revolution which is the topic of discussion in various walks of life. However, at present the challenges have reached the stage of 5.0 Industrial Revolution. The era society 5.0 was first introduced by Japanese prime minister Shinzo Abe with the aim of balancing technological progress with the resolution of integrated social problems. Sociologically, technology is one aspect that also influences every activity, action, and human behavior [1], [2]. Technology is able to change the pattern of relationships and patterns of interaction between humans. Today's technological advancements are characterized by increasingly sophisticated tools in the fields of information and communication, satellites, biotechnology, agriculture, equipment in the health sector, and genetic engineering. The emergence of digital society in various fields of life is evidence of technological progress. Communities and countries in the world are competing to master high technology as a symbol of progress, power, wealth and prestige [3].

In the document "Realizing Society 5.0" powered by News Picks Brand Design (In [3] stated "This is Society 5.0, a super-smart society. Japan will take the lead to realize this ahead of the rest of the world." This is a very optimistic and visionary statement in the midst of the world focusing on Industry 4.0 (Use of Technology, Data and Automation) [4] and [5]. Touch 
of humanism in Society 5.0 will be the basic capital of this concept will be accepted by the world community. , the concept of Society 5.0 was triggered by a serious problem that Japan possessed, namely a decrease in the number of population [3] Online page Kompas.com $1 / 2019$, stated that currently the Japanese population is productive at 77 million and will be reduced by 70 percent to 53 million in 2050 . While on the other hand, populations over the age of 65 will increase by 38.4 percent by 2065 . This Society 5.0 is a blueprint and future strategy that is very suitable for breaking down the selfishness of countries other than Japan for the Industrial Revolution 4.0. In the midst of the many jobs lost due to automation and capitalism that are applauded because effectiveness and efficiency can be realized, Society 5.0 becomes a fresh wind of change [6].

\section{Problems}

How should the Age of 5.0 be a great opportunity for Indonesia to accelerate the transformation of its society. It is not a problem for Indonesia to stand on two legs, the Industrial Revolution 4.0 and Society 5.0. both of these momentum must be combined into a national blue print.

How to Make appropriate policies relating to the advancement of technology in the Government towards the information society in a technologically wise, economical, and environmentally friendly manner.

How the Education System is able to collaborate to form a complete system, namely the chronosystem capable of strengthening the new literacy movement (digital literacy, technology literacy and human literacy) and what the 5.0 Role of Society in Human Life is like.

\section{Study of theory}

\subsection{Definition of the Information Society}

Information society is a term used to describe a society and an economy that can make the best possible use of new information and communication technologies (ICT's). In the information society people will benefit fully from new technologies in all aspects of life. The development of educational humanisties, for example, must involve all stakeholders involved in the system to address the challenges of industry 4.0. Brofenbrener [5], [7] offer a model called the A Bioecological Model of Human Development. All stakeholders involved in the system to address the challenges of industry 4.0. Brofenbrener [5], [7] offer a model called the A Bioecological Model of Human Development. 


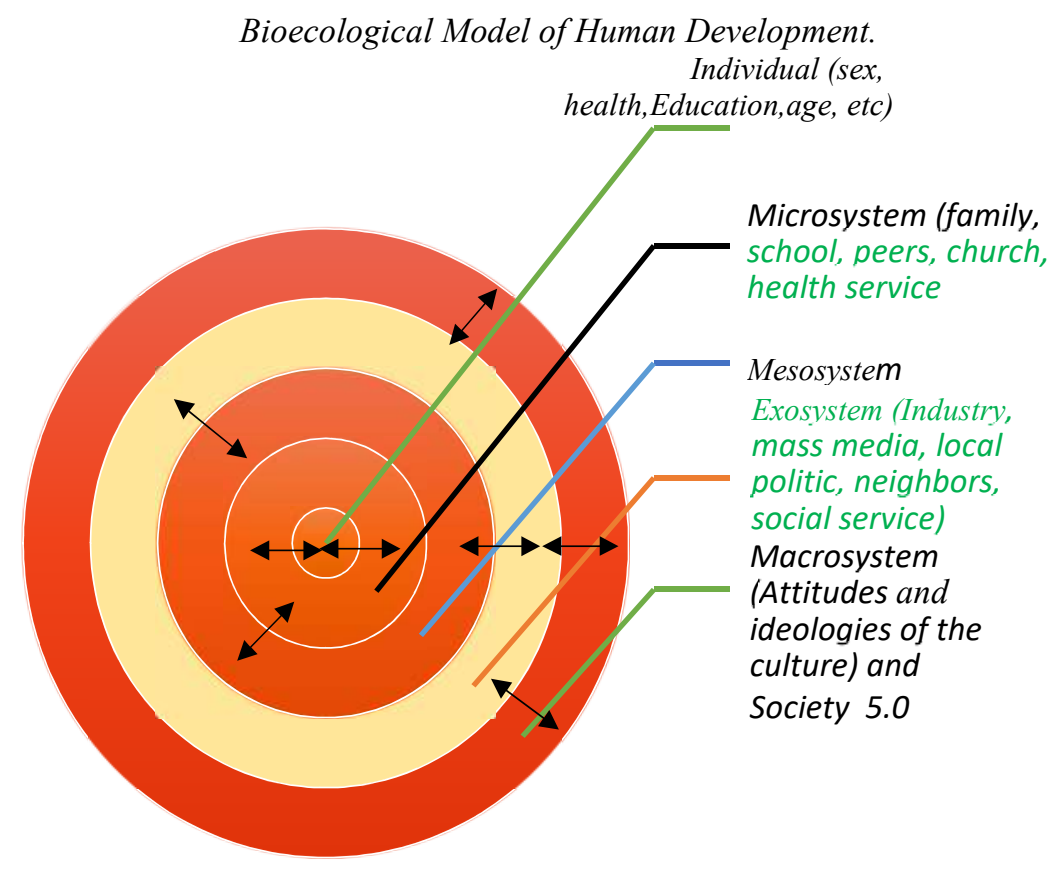

Fig. 1. A Bioecological Model Human Development (Sumber: Broffenbrenner, 1989)

In Figure 1, it can be seen that all parts of the system, individuals, micro systems, systems, such as industry, mass media, social services, and local politics, and macro systems must be able to collaborate to form a complete system, namely the chronosystem. The element must be involved in the system, especially in the field of education (learning, education units, students, and educators and education staff) in accordance with their respective roles. Elements that interact in the chronosystem must integrate the focus of the industrial era 4.0 namely, physical, digital, and biological. Elements that exist in education as part of the chronosystem must strengthen the new literacy movement (digital literacy, technology literacy, and human literacy). Strengthening is done to provide added value and competitiveness of education graduates in the industrial era 4.0. Interaction and integration between elements with industrial content 4.0

In terms of resources and infrastructure according to Nugroho [5], [6], information from the community is at least: (1) Broadband telecommunications network infrastructure that is affordable for the public; (2) User communities and information providers; (3) Human resources skilled in information technology; (4) Diverse information technology industries; (5) Authority that regulates information technology. 


\section{Discussion}

\subsection{The Age of Society 5.0 must be a great opportunity for Indonesia}

Understanding information society is a state of society where the production, distribution and manipulation of information becomes the main activity, meaning that information processing is the core of new technological activities has implications for all aspects of society and economics, technology changes how to do business, how to learn, how to use leisure time [3], [4]. This means an important challenge for the government: (1) Laws need to be updated in terms of supporting electronic transactions (2) Communities need to be educated about new technologies. (3) Changes in the characteristics of work patterns, people always seek information and knowledge in order to work quickly, effectively and efficiently. (3) Changes in how to disseminate knowledge, ranging from the conventional to the dissemination of information using sophisticated tools. (4) Change in how to find knowledge, the greater the curiosity in a person so that they try to get information specifically. (5) Progress in creating tools to disseminate and access new knowledge. The five factors are oriented to the need to get information in accordance with the wishes and needs of information seekers.

According to Sutarno [3], the characteristics of information society are: (1) Sources of information affordable by all levels of society; (2) There is public awareness about the importance of information in various life activities. (3) Open views and insights of the community in using information technology appropriately. The development of library institutions, documentation and information evenly. (4) Progress of human, information and physical resources that utilize science and technology. (6) Information managed properly, presented on time and packaged with technology can be developed as a commodity of economic value.

In terms of resources and infrastructure according to Nugroho [5], [6], information from the community is at least: (1) Broadband telecommunications network infrastructure that is affordable for the public; (2) User communities and information providers; (3) Human resources skilled in information technology; (4) Diverse information technology industries; (5) Authority that regulates information technology.

\subsection{Steps that need to be taken to reach the information community}

Improvement of information and communication technology infrastructure; It is necessary to conduct research on the social, cultural and educational conditions of the local community to determine the level of enthusiasm and awareness of the community, so that groups of people who are ready and not ready can be distinguished, and periodically create programs for the information society

Determination of regulations and policies, the government must begin to design various basic regulations and policies.

Organizing WSIS (World Summit of Information Society: World Conference for Information Society) WSIS has encouraged countries in the world to develop ICT applications in their respective countries through various policies that condition people in each country to become information technology literacy. The results can see a very significant development in the last ten years, where the use of ICT, for example cell phone use, whose user ratio has reached 78/100 people compared to 2000 which was only 10/100.

\subsection{The Education System is able to collaborate to form a complete system.}

Industry 4.0 brings many changes in human life. Industry 4.0 has fundamentally changed the way people move and has a big influence on the world of work, including the education 
system that forms a chronosystem capable of strengthening the new literacy movement. In Indonesia itself, the government sets 10 targets related to the Global Information Society, namely: (1) Connecting all stakeholders with ICT and building various Community Access Centers; (2) Connecting all elementary and secondary schools with ICT; (3) Linking all scientific research and development centers with ICTs; (4) Connecting all public libraries, museums, post offices, and national archive centers with ICTs; (5) Connecting all health centers and hospitals with ICTs; (6) Linking all central government ministries with ICTs and developing various websites related to their tasks; (7) Adjusting the primary and secondary school curriculum so that students will be ready to become individuals. be in an informationbased community, according to national environmental conditions and conditions; (8) Ensure that all populations in the country have access to television and radio broadcasts; (9) Giving encouragement and incentives to the ICT content development industry and preparing technically the use of various world languages through internet-based communication; (10) Ensure that more than half of the world's population already has access to ICT in their environment and is able to use and use it. And Factors that need to be considered towards the information society [2].

\section{Conclusion}

Along with the rapid development of technology, the use of technology has begun to increase its role in human life and the era of society 5.0 is an era where technology is very close to human life. To welcome the public 5.0 technology must be developed from the basis of one of the population governance systems so as to facilitate the integration of community services such as education and health. Education must be able to equip graduates with these three literacies through the revitalization of the chronosystem which includes learning systems, educational units, students, and educators and education staff. In the 5.0 Industrial Revolution, there will be aspects that will restore the glory of human civilization. The Founder of Malindo (Malaysia-Indonesia) Research Center for CSR and Leadership said, the aspects that collaborate with each other are physical, digital and biological, and are complemented by the presence of spiritual aspects. During this 5.0 Industrial Revolution, religion will return to lead science again. Thus Society 5.0 is Indonesia's New Future.

\section{Reference}

[1] M. Fukuyama, "Aiming for a New Human-Centered Society," Intell. Glob. Japan, 2018.

[2] R. E. Indrajit, Framework for Designing and Building Smart Cities throughout the Archipelago. EKOJII999 Number 001, 2012.

[3] N. P. Premierita, "Challenges in Indonesia:Towards the Information Society of the Faculty of Social Sciences and Political Sciences at Udayana University," 2016.

[4] R. Bustami, "Material of Industrial Revolution 5.0 was delivered to guest lectures," 2018.

[5] F. N. S. Damanik, "Become an Information Society," JSM STMIK Microsc., vol. 31, no. 4, pp. 73-82, 2012.

[6] L. Z. Karvalics, Information Society: From Theory to Political to Practice. Japan, 2008.

[7] S. Serpa and C. M. Ferreira, "Society 5.0: Innovation, Uncertainty and Social Sciences," 2018. [Online]. Available: http://www.mdpi.com/journal/socsci/special_issues/Society_5.0. 